\title{
EFFECT OF AN INTRA-UTERINE DEVICE ON ENDOMETRIAL MORPHOLOGY AND THE DECIDUOMAL REACTION IN THE RHESUS MONKEY
}

\author{
W. A. KELLY, ${ }^{*}$ J. H. MARSTON $\dagger$ AND P. ECKSTEIN \\ Department of Anatomy, Medical School, Birmingham 15
}

(Received 8th Fuly 1968)

\begin{abstract}
Summary. Morphological observations made on forty-nine uteri from twenty-three control and twenty-six IUD rhesus monkeys killed between Days 15 and 20 of their natural menstrual cycle, were related to the physiological condition of the corresponding ovary.

The only differences between control and IUD specimens of similar luteal age were the presence of (a) a markedly flattened surface epithelium in areas of contact with the IUD; (b) erosion of the surface epithelium and underlying stroma, with fibrosis and extensive leucocytic infiltration, in the lateral angles of the uterine lumen; (c) polymorphonuclear leucocytes lying immediately beneath the surface epithelium, together with variable leucocytic infiltration into the epithelium and the underlying stroma. These changes were not related to the physiological state of the ovary, previous surgery of the uterus, or to the length of time the IUD was retained in the uterine lumen.

A deciduomal reaction could be induced both in ovariectomized, hormonally-stimulated and in naturally cyclic monkeys as a response to endometrial trauma. In both groups, there was no difference in the appearance and proliferation of the deciduomal reaction in control and IUD monkeys.
\end{abstract}

\section{INTRODUCTION}

A number of studies have been made on the endometrial morphology of rhesus monkeys fitted with intra-uterine devices (IUDs) (Kar, Chowdhury, Kamboj, Chandra \& Chowdhury, 1965, 1967; Kar, Kamboj, Chandra \& Karkun, 1966; Tamada \& Sturgis, 1966). In addition, the gross effects of an IUD on endometrial morphology immediately after insertion have been recorded by Kar \& Chandra for both the mature, cyclic (1965) and the pre-pubertal monkey (1967).

So far, however, there have been no attempts to correlate the endometrial

\footnotetext{
* Present address: Department of Anatomy, The University, Bristol BS8 ITD.

† Present address: Physiological Laboratory, Cambridge CB2 3EG.
} 
morphology of the IUD rhesus monkey with the functional state of the ovary, and the time of the IUD's contraceptive action.

Bartelmez (1951) has provided the most thorough study of endometrial morphology in normal rhesus monkeys at varying stages of the menstrual cycle. A deciduomal reaction has been induced in rhesus monkeys (Hisaw, 1935; Hisaw, Greep \& Fevold, 1937) and has been most extensively studied by Rossman (1940). Rossman's term 'deciduomal' has been retained in the present study to distinguish the epithelial reaction of the endometrium to trauma in the rhesus monkey from the stromal, decidual cell reaction which occurs in rodents.

This paper is the fifth in a series of communications dealing with the effects of an IUD on conception in the rhesus monkey. It reports our observations on (a) the morphology of the endometrium as related to that of the ovary, and the time of the IUD's contraceptive action, and (b) the induction of a deciduomal reaction in control and IUD monkeys.

\section{MATERIALS AND METHODS}

Full details of the management and preparation of the rhesus monkeys used in the series of experiments have been described by Eckstein, Kelly \& Marston (1969).

\section{Endometrial morphology}

Observations were made on a series of forty-nine uteri from twenty-three control and twenty-six IUD rhesus monkeys killed between Days 15 and 20 of their natural menstrual cycle. In all of the specimens, the morphology of the endometrium was compared with that of the ovary and/or the corpus luteum (Kelly, Marston \& Eckstein, 1969).

The monkeys, all of which had previously shown regular menstrual cycles, were killed in the course of other experiments which sometimes necessitated surgical interference involving the uterine lumen (Marston, Kelly \& Eckstein, $1969 \mathrm{a}, \mathrm{b})$. Of the control uteri, three had been irrigated with saline during a previous menstrual cycle, fourteen had been subjected to egg transfer during the current cycle, and six had not received any interference. Apart from the interference inevitably associated with insertion of an IUD, six IUD uteri had not received any additional interference, four had been irrigated and sixteen had received egg transfers during the current menstrual cycle.

All of the uteri were obtained from monkeys which had been mated with fertile males during the current menstrual cycle. None of the IUD uteri had contained an IUD for less than 1 month or one completed menstrual cycle. Fourteen uteri had contained an IUD for more than 12 months (12 to 22 months), four for 6 to 12 months, and eight for 1 to 6 months.

At autopsy, the uterine lumina were routinely flushed with Ringer's solution to recover eggs and embryos. The uterus was then carefully incised and opened so that the surface of the endometrium could be examined for the presence of gross abnormalities. The position of the IUD was noted before it was removed.

Appropriate specimens were removed from the dorsal and/or the ventral halves of the uteri for fixation in aqueous Bouin's solution and $10 \%$ buffered 
neutral formol. Transverse sections were cut at $8 \mu$ and stained with haematoxylin and eosin, by the PAS and Alcian blue techniques and by the oil red $\mathrm{O}$ technique.

\section{Deciduomal reaction}

An attempt was made to induce a deciduomal reaction in control and IUD rhesus monkeys. Initially, ovariectomized, hormonally-stimulated monkeys were used but later the experiment was performed on intact, naturally cyclic animals.

Ovariectomized monkeys. Three control and three IUD monkeys, which had been fitted with IUDs for 10 to 17 months, were ovariectomized and subsequently treated by daily intramuscular injection with:

$50 \mu \mathrm{g}$ Oestradiol di-propionate (ODP) on Days 1 to 3;

$75 \mu \mathrm{g}$ ODP on Days 4 to 6 ;

$100 \mu \mathrm{g}$ ODP plus $5 \mathrm{mg}$ progesterone on Days 7 to 10 followed by

$10 \mathrm{mg}$ progesterone daily until the end of the experiment.

On Day 16 of this treatment, the uteri were traumatized by placing a vertical mattress suture through the ventral and dorsal surfaces of the uterus, using 3-0 silk. The threads were pulled to and fro three times and then withdrawn. The monkeys were killed 15 days after traumatization, and their uteri were removed for routine histological examination (see above).

Cyclic monkeys. Two control and two IUD monkeys were used. They had all previously shown regular menstrual cycles and their uteri were traumatized on menstrual Day 20 or 22. The animals all had a prominent corpus luteum at the time of trauma and they were killed $96 \mathrm{hr}$ later. The IUD monkeys had been fitted with IUDs for 18 months before this experiment.

\section{Endometrial morphology}

\section{OBSERVATIONS}

Table 1 summarizes the observations on the morphology of the ovaries from the control and IUD monkeys used in this study. The age of the corpus luteum is an estimate based upon careful examination of its histological structure in comparison with the exactly timed series of corpora lutea reported by Corner (1945) and our own series of timed ovulations (Kelly et al., 1969).

The endometrial morphology of control monkeys did not differ from the pattern described by Bartelmez (1951), and there was no indication in any specimen that it had been altered by surgical interference during the current cycle or in previous cycles.

Certain specific changes were noted in the morphology of the surface epithelium and its immediately adjacent stroma in the endometria of the IUD monkeys. No significant histological changes in relation to the age of the corpus luteum were found in the glandular epithelium and the endometrial stroma.

As judged by the results of the PAS, Alcian blue and oil red $\mathrm{O}$ staining techniques, there was no difference in the distribution of glycogen, acid mucopolysaccharides and lipid in control and IUD specimens of the same luteal 
age. The distribution of mitoses in the glandular epithelium of control and IUD uteri was also correlated with the condition of the ovary (cf. Bensley, 1951). When allowance was made for overall variations in size, no difference could be detected in the growth and development of the glands and the thickness of the endometrium in control and IUD specimens of similar luteal age (Pl. 1, Figs. 1 to 4 ).

The IUD specimens usually showed a prominent lesion in the lateral angle of the uterine lumen (Pl. 1, Figs. 5 and 6). There was erosion of the surface epithelium and the underlying endometrial stroma, with fibrosis and extensive leucocytic infiltration into the lesion. It appeared that leucocytes were passing into the uterine lumen.

This lesion was probably caused by pressure atrophy, and it was noted at autopsy that the IUDs had caused deep indentation of the endometrium in the lateral angles of the uterine lumen. Seven monkeys had been fitted with the relatively oversized Type 2 IUD (cf. Eckstein et al., 1969), and they showed more extensive damage. The other monkeys had been fitted with the Type 3 IUD which was more in proportion with the dimensions of the uterine lumen but even in these cases the IUD exerted pressure on the lateral angles of the lumen.

\section{TABLE 1}

CONDITION OF THE OVARIES ASSOCIATED WITH THE UTERINE SPECIMENS

\begin{tabular}{|c|c|c|c|c|c|c|c|c|c|c|c|}
\hline \multirow{4}{*}{ Group } & \multirow{4}{*}{$\begin{array}{c}\text { Total } \\
\text { specimens }\end{array}$} & \multicolumn{10}{|c|}{ Ovarian condition } \\
\hline & & \multirow{3}{*}{ Inactive $\uparrow$} & \multirow{3}{*}{ Pre-ovulatory } & \multicolumn{8}{|c|}{ Ovulated } \\
\hline & & & & \multirow{2}{*}{ Total } & \multicolumn{7}{|c|}{ Estimated age of corpus luteum* (days) } \\
\hline & & & & & 2 & 3 & 4 & 5 & 6 & 7 & 8 \\
\hline $\begin{array}{l}\text { Control } \\
\text { IUD }\end{array}$ & $\begin{array}{l}23 \\
26\end{array}$ & $\begin{array}{l}4 \\
5\end{array}$ & $\overline{2}$ & $\begin{array}{l}19 \\
19\end{array}$ & $\begin{array}{l}4 \\
1\end{array}$ & $\begin{array}{l}2 \\
3\end{array}$ & $\begin{array}{l}3 \\
3\end{array}$ & $\begin{array}{l}4 \\
2\end{array}$ & $\begin{array}{l}5 \\
5\end{array}$ & $\begin{array}{l}1 \\
4\end{array}$ & $\overline{1}$ \\
\hline
\end{tabular}

* Lowest estimate, i.e. corpus luteum cannot be younger than this age.

$\dagger$ Includes ovaries with large atretic follicles.

At autopsy, the IUD specimens had shown indentations wherever the IUD had been in contact with the endometrial surface. The indentations were deeper in the uteri that had been fitted with the Type 2 IUD. At histological examination, the areas of contact with the IUD were characterized by an extremely flattened epithelium (Pl. 2, Figs. 7, 8, 10,11 and 13). The surface epithelium usually showed a graduation from the extremely flattened epithelium of the 'contact' areas to apparently normal pseudo-stratified epithelium in the 'non-contact' areas (Pl. 2, Fig. 9). The contact areas accounted for a large proportion of the total epithelial surface, but non-contact areas were always present. The shape of the IUDs and their size in relation to that of the uterine lumen ensured that all of the non-contact areas had, in fact, been enclosed between the coils of the IUD. Stromal oedema could not be detected in the non-contact areas and consolidation of the stroma was usually not obvious 
beneath the contact areas except in specimens which had been fitted with Type 2 IUDs. A layer of fibrosis was present in the stroma underlying contact areas in the Type 2 IUD specimens. The appearance of the surface epithelium suggested that it had probably been intact in all the IUD specimens, although removal of the IUD at autopsy had inevitably caused some damage to the surface. Erosion of the epithelium could only be detected in the lateral angles of the uterine lumen.

The most notable finding in all of the IUD specimens was the presence of polymorphonuclear leucocytes immediately beneath the basement membrane of the surface epithelium (Pl. 2, Figs. 12 and 13). Some of these leucocytes appeared to be passing through the epithelium into the uterine lumen, and there was a variable amount of leucocytic infiltration into the underlying stroma. The leucocytes were most prominent beneath the severely flattened epithelium of the contact areas, but they could also be found beneath the pseudo-stratified epithelium of the non-contact areas. Most of the leucocytes were enclosed within thin-walled channels lying close to the basement membrane of the surface epithelium. Leucocytic infiltration was not observed beneath the glandular epithelium.

It must be emphasized that sub-epithelial leucocytes were not detected in any of the control specimens but were constantly present in the IUD specimens. Their presence and distribution in the IUD uteri was not related to the condition of the ovary, to the surgical history of the individual uterus, or to the length of time that an IUD had been present within the uterine lumen.

\section{Endometrial vasculature}

No obvious differences could be detected in the distribution of the coiled arteries in the endometria of similar age in controls and IUD monkeys. A thin-walled, vascular channel could usually be detected beneath the surface epithelium in IUD specimens at times when there were no capillaries beneath the basement membrane of control specimens. The vascular channel was not distinct in the two IUD specimens associated with ovaries in the pre-ovulatory condition, even though leucocytes were present. Small channels could be identified in the IUD specimens associated with inactive ovaries. The channels were particularly prominent in contact areas of IUD specimens that had an active corpus luteum.

\section{Myometrial morphology and vasculature}

Although detailed studies were not performed, gross differences could not be detected between the myometrial morphology and vasculature of control and IUD specimens.

\section{The deciduomal reaction}

The six ovariectomized monkeys all showed a prominent deciduomal reaction (Pl. 3, Figs. 14, 15 and 16), which had spread beyond the limits of the site of trauma as an epithelial plaque. There was no difference in the extent and the morphological appearance of the deciduomal reaction in the control and IUD specimens. 
In the two control monkeys traumatized during their natural menstrual cycle, an obvious deciduomal reaction was obtained (Pl. 3, Figs. 17 and 18). One specimen (Pl. 3, Fig. 17) showed an early stage in its development with 'proliferation cells' characteristic of the 'metaplastic reaction' (Rossman, 1940) lying at the base of the surface epithelium. This reaction had progressed in the other specimen to involve the glandular epithelium.

One of the naturally cyclic IUD monkeys showed a pronounced deciduomal reaction which had involved the glandular epithelium (Pl. 3, Fig. 19). The second IUD animal, however, did not show any reaction. Its corpus luteum differed from those in the other naturally cyclic monkeys, and appeared to be degenerating.

The epithelial changes associated with the deciduomal reaction in both the control and the IUD monkeys were similar and consistent with the observations of Rossman (1940).

\section{Endometrial morphology}

\section{DISCUSSION}

Previous studies have shown that although an IUD did not affect ovulation and fertilization, it was contraceptive in the rhesus monkey. The pattern of tubal transport was not markedly disturbed, but eggs could not usually be recovered from the uterus. It was inferred that the principal contraceptive effect of an IUD was probably exerted within the uterus to cause premature destruction of the fertilized egg (Kelly \& Marston, 1967; Marston \& Kelly, 1968).

The present study has revealed marked differences in endometrial morphology between control and IUD uteri of similar age as determined by dating the corpus luteum. These differences are the presence of (a) a markedly flattened surface epithelium in areas of contact with the device, (b) erosion of the surface epithelium and underlying stroma with fibrosis and extensive leucocytic infiltration in the lateral angles of the uterine lumen, and (c) polymorphonuclear leucocytes lying immediately beneath the surface epithelium, together with variable leucocytic infiltration into the epithelium and the underlying stroma in uteri of IUD monkeys and their absence in uteri of controls.

These results are in marked contrast to those of other workers. Kar et al. $(1965,1967)$ found no histological or histochemical changes in the endometria of IUD monkeys examined either at 90 days (1965) or 545 days (1967) after insertion of a device. An increase in the rate of oxygen consumption of the endometrium present at 90 days had disappeared at 545 days, suggesting that biochemical adaptation of the uterus to the presence of the device had taken place during the intervening period.

Tamada \& Sturgis (1966) observed that in three ovariectomized rhesus monkeys, the presence of an IUD for 14 weeks caused pressure atrophy of the endometrial epithelium but did not alter the endometrial response to exogenous ovarian steroids. By contrast, Kar et al. (1966) found that the endometrial response to exogenous oestrogen was histologically and biochemically similar in ovariectomized control and IUD monkeys.

In the present observations on IUD monkeys, thin-walled vascular channels 
were usually visible beneath the basement membrane of the surface epithelium in endometria that were associated with an active corpus luteum. Kar \& Chandra $(1965,1967)$ noted the transitory development of similar vessels during the period of bleeding which followed immediately upon insertion of an IUD. These vessels had disappeared by 5 days after the end of this bleeding.

\section{Endometrial development}

It has been widely appreciated that an IUD may exert its contraceptive effect in women by advancing or retarding the rate of development of the endometrium (cf. Segal, Southam \& Shafer, 1965). Most studies on endometrial specimens have attempted to show whether they were 'in phase' or 'out of phase' with the pattern of normal endometrial development described by Noyes, Hertig \& Rock (1950). But studies based only upon the examination of endometrial biopsies have limited value and may not, in the opinion of some workers (e.g. Bonney, Glasser, Clewe, Noyes \& Cooper, 1966), be worthwhile. Work on entire uteri, obtained at hysterectomy, is far more satisfactory, as the histological findings can be related with precision to the position of the IUD.

Those workers who have used hysterectomy specimens consider that, in the presence of an IUD, there is no substantial alteration in the rate of morphological development of the endometrium in the human subject (Israel \& Davis, 1966; Morese, Peterson \& Allen, 1966). They observed that the IUD specimens usually showed (a) flattening of the surface epithelium in contact with the IUD and fibrosis of the underlying stroma, (b) progressive oedema, during the secretory phase of the menstrual cycle, of the endometrium enclosed by the device, with development of thin walled vascular channels beneath the surface epithelium, and (c) a variable, low grade, leucocytic infiltration into the epithelium and stroma in contact with, or immediately adjacent to the IUD. Bonney $e t$ al. (1966), while agreeing that these changes occurred, found that there was also evidence of retardation in the biochemical maturation of the endometrium.

In marked contrast with these consistent results are the observations based on the study of endometrial biopsy specimens. Hall, Sedlis, Chabon \& Stone (1965), Willson, Ledger \& Andros (1965), Lee, Chow, Cheng \& Wei (1967) and Sammour, Iskander \& Rifai (1967) found that in the presence of an IUD there was delayed maturation of the endometrium during the secretory phase of the cycle. Tamada, Okagaki, Maruyama \& Matsumoto (1967) noted that the morphological development of endometria was retarded only in areas that were in contact with the device. Abrams \& Spritzer (1966) and Rozin, Sacks \& Shenker (1967) did not usually observe significant alterations in their biopsies, but Wynn (1967) found ultra-structural evidence that the development of epithelium was actually advanced in some, but not all, of his specimens.

Bartelmez (1951) has shown that there is no clearly defined correlation between the endometrium and the ovarian cycle in the rhesus monkey, and it has been impossible in the present study to come to any conclusion concerning similarities or differences between endometrial development in control and IUD specimens of identical luteal age. It is not known whether they were 'in phase' or 'out of phase' with one another and with the physiological events of the menstrual cycle. 
While the present findings provide clear evidence of endometrial damage in the presence of an IUD, it cannot be proved that these changes were sufficient, in themselves, to explain the contraceptive action of the IUD. Biochemical studies on the function of the endometrium during the pre-implantation period may eventually establish a meaningful relationship between the observable effects and the actual mode of action of an IUD in the rhesus monkey.

\section{Deciduomal reaction}

No deciduomal reaction was observed in the uterine specimens used to study the effect of an IUD on endometrial morphology, most of which had been subjected to surgical interference for egg transfer on Day 15 of their current menstrual cycle. Traumatization at this time was probably performed before the uterus had become sensitized for the induction of a deciduomal reaction (Rossman, 1940).

Attempts to induce a deciduomal reaction in IUD monkeys were made because this was the only means of assessing the capacity of the endometrium to respond to a stimulus during the implantation period. Hisaw (1935) first pointed out the similarity between the endometrial reaction to trauma and the natural reaction during the early stages of implantation. He realized that the deciduomal reaction was derived from the surface epithelium and glands of the endometrium, and not from the endometrial stroma. Wislocki \& Streeter (1938) confirmed that during implantation there was pronounced epithelial proliferation to form an epithelial 'plaque', and Rossman (1940) established that this epithelial proliferation was comparable to that produced by trauma. The deciduomal reaction in the rhesus monkey has a purely epithelial origin and is not strictly comparable with the stromal decidual reaction which occurs in women and rodents (DeFeo, 1967).

While implantation in the rhesus monkey is superficial, in women it is interstitial. This and several other major differences between the mechanism of implantation in the two species (Ramsey \& Harris, 1966) may have considerable importance in modifying the contraceptive action of an IUD.

The finding that the uterus of an IUD monkey was able to produce an extensive deciduomal reaction when traumatized during the sensitive implantation period does not necessarily mean that uterine function was unchanged in the presence of an IUD. During natural implantation, only the surface epithelium of the endometrium is stimulated by the blastocyst. By contrast, experimental induction of the deciduomal reaction by trauma involves injury to the surface epithelium and also to the superficial and deep glandular epithelium. Here, the individual contributions of the surface and glandular epithelium to the epithelial plaques formed in both the IUD and the control monkeys could not be distinguished, though it may be possible to produce a more physiological deciduomal reaction in IUD and/or control monkeys by specifically stimulating the surface epithelium. This work is in progress.

\section{ACKNOWLEDGMENTS}

This work was supported by a grant from the Ford Foundation, New York, whose help we gratefully acknowledge. 
The histological techniques were expertly performed by Miss Margaret Giles, who, with $\mathrm{Mr}$ J. Browning, has given us constant assistance. Mr H. Smith, Mr F. James and Mr G. Tonks were responsible for the care and supervision of the rhesus monkeys.

\section{REFERENCES}

Abrams, R. Y. \& SPRITZER, T. (1966) Endometrial cytology in patients using intra-uterine contraceptive devices. Acta cytol. 10, 240.

Bartelmez, G. W. (1951) Cyclic changes in the endometrium of the rhesus monkey (Macaca mulatta). Contr. Embryol. 34, 101.

Bensley, G. M. (1951) Cyclic fluctuation in the rate of epithelial mitosis in the endometrium of the rhesus monkey. Contr. Embryol. 34, 87.

Bonney, W. A., Glasser, S. R., Clewe, T. H., Noyes, R. W. \& Cooper, G. L. (1966) Endometrial response to the intrauterine device. Am. 7. Obstet. Gynec. 96, 101.

Corner, G. W. (1945) Development, organisation and breakdown of the corpus luteum in the rhesus monkey. Contr. Embryal. 31, 117.

De Feo, V. (1967) Decidualization. In: Cellular Biology of the Uterus, Ch. 8. Ed. R. M. Wynn. North Holland Publishing Co., Amsterdam.

Eckstein, P., Kelly, W. A. \& Marston, J. H. (1969) Effect of an intra-uterine device on menstrual periodicity in the rhesus monkey. F. Reprod. Fert. 19, 133.

Hall, H. H., Sedlis, A., Chabon, I. \& StONe, M. L. (1965) Effect of intra-uterine stainless steel ring on endometrial structure and function. Am. F. Obstet. Gynec. 93, 1031.

Hisaw, F. L. (1935) The physiology of menstruation in macacus rhesus monkeys: 1. Influence of the follicular and corpus luteum hormones. 2. Effects of anterior pituitary extracts. Am. 7. Obstet. Gynec. 29, 638.

Hisaw, F. L., GREeP, R. O. \& FEvold, H. L. (1937) The effects of oestrin-progestin combinations on the endometrium, vagina and sexual skin of monkeys. Am. F. Anat. 61, 483.

IsRaEL, R. \& DAVIS, H. F. (1966) Effects of intra-uterine contraceptive devices on the endometrium. 7. Am. med. Ass. 195, 764.

KAR, A. B. \& ChANDrA, H. (1965) Uterine bleeding in rhesus monkeys after insertion of an intrauterine device. Indian F. exp. Biol. 3, 269.

KAR, A. B. \& CHANDRA, H. (1967) Uterine bleeding in prepubertal rhesus monkeys after intra-uterine contraceptive device insertion. Am. F. Obstet. Gynec. 97, 279.

Kar, A. B., Chowdhury, S. R., KamboJ, V. P., Chandra, H. \& Ghowdhury, A. R. (1965) Effect of an intra-uterine contraceptive device on the uterus of rhesus monkeys. Int. F. Fert. 10, 321.

Kar, A. B., Kamboj, V. P., Chowdhury, S. R., Chandra, H. \& Ghowdhury, A. R. (1967) Long-term effect of an intrauterine contraceptive device on the uterus and Fallopian tubes of rhesus monkeys. Am. F. Obstet. Gynec. 98, 194.

Kar, A. B., KamboJ, V. P., Chandra, H. \& Karkun, J. N. (1966) Effect of an intra-uterine contraceptive device on sensitivity of uterus and Fallopian tubes of ovariectomized rhesus monkeys to estrogen. Indian 7. exp. Biol. 4, 171.

Kelly, W. A. \& MARston, J. H. (1967) Action of intra-uterine devices in rhesus monkeys. Nature, Lond. 214, 735.

Kelly, W. A., Marston, J. H. \& Eckstein, P. (1969) Effect of an intra-uterine device on conception and ovulation in the rhesus monkey. F. Reprod. Fert. 19, 143.

LeE, G. H., Ghow, L. P., Cheng, T. Y. \& WEI, P. Y. (1967) Histologic study of the endometrium of IUD users. Am. F. Obstet. Gynec. 98, 808.

Marston, J. H. \& Kelly, W. A. (1968) Effect of an intra-uterine device on uterine motility in the rhesus monkey. Nature, Lond. 217, 774 .

Marston, J. H., Kelly, W. A. \& Eckstein, P. (1969a) Effect of an intra-uterine device on gamete transport and fertilization in the rhesus monkey. $\mathcal{F}$. Reprod. Fert. 19, 149.

Marston, J. H., Kelly, W. A. \& Eckstein, P. (1969b) Effect of an intra-uterine device on uterine motility in the rhesus monkey. F. Reprod. Fert. 19, 321.

Morese, K. N., Peterson, W. F. \& Allen, S. T. (1966) Endometrial effects of an intra-uterine contraceptive device. Obstet. Gynec., N.Y. 28, 323.

Noyes, R. W., Hertig, A. T. \& Rock, J. (1950) Dating the endometrial biopsy. Fert. Steril. $1,3$.

RAMSEY, E. M. \& HARRIS, J. W. S. (1966) Comparison of uteroplacental vasculature and circulation in the rhesus monkey and man. Contr. Embryol. 38, 60.

Rossman, I. (1940) The deciduomal reaction in the rhesus monkey (Macaca mulatta). I. The epithelial proliferation. Am. F. Anat. 66, 277. 
Rozin, S., SACKs, M. I. \& SHenker, J. G. (1967) Endometrial histology and clinical symptoms following prolonged retention of uterine contraceptive devices. Am. 7. Obstet. Gynec. 97, 197.

Sammour, M. B., Iskander, S. G. \& Rifai, S. F. (1967) Combined histologic and cytologic study of intra-uterine contraception. Am. 7. Obstet. Gynec. 98, 946.

Segal, S. J., Southam, A. L. \& Shafer, K. D. Eds. (1965) Proc. 2nd int. Conf. Intra-uterine Contraception, New York. Excerpta med. int. Conf. Ser. No. 86.

Tamada, T. \& Sturgis, S. H. (1966) The endometrium of hormone stimulated castrated monkeys bearing an intra-uterine device. Obstet. Gynec., N.Y. 28, 793.

Tamada, T., Okagaki, T., Maruyama, N. \& Matsumoto, S. (1967) Endometrial histology associated with an IUD. Am. F. Obstet. Gynec. 98, 811.

Willson, J. R., LEDGer, W. J. \& ANDros, G. J. (1965) The effect of an intra-uterine contraceptive device on the histologic pattern of the endometrium. Am. F. Obstet. Gynec. 93, 802.

Wrslocki, G. B. \& Streeter, G. L. (1938) On the placentation of the macaque (Macaca mulatta) from the time of implantation until the formation of the definitive placenta. Contr. Embryol. 27, 1.

WrnN, R. M. (1967) Intra-uterine devices: effects on ultrastructure of human endometrium. Science, N.Y. 156, 1508.

\section{EXPLANATION OF PLATES}

Magnification figures are approximate in each Plate.

\section{PLATE 1}

All the figures are photographs of $8 \mu$ paraffin sections stained with $\mathrm{H}$ and $\mathrm{E}$.

Frg. 1. Endometrium of control monkey yielding a nine-celled egg from the uterus: corpus luteum aged 4 to 6 days. $\times 10$.

Fig. 2. Endometrium of IUD monkey yielding a degenerate, unfertilized egg from the uterus: corpus luteum aged 6 days. $\times 10$.

FIG. 3. Endometrium of control monkey yielding an early blastocyst from the uterus: corpus luteum aged 7 days. $\times 10$.

FIG. 4. Endometrium of IUD monkey: corpus luteum aged 7 days: no egg recovered. $\times 10$.

Fig. 5. Lateral angle of control uterine lumen. $\times 50$.

FIG. 6. Lateral angle of uterine lumen in IUD monkey to show erosion and fibrosis. $\times 50$.

\section{PLATE 2}

All the figures are photographs of $8 \mu$ paraffin sections stained with $\mathbf{H}$ and $\mathbf{E}$.

Fig. 7. Surface and glandular epithelium of control endometrium. $\times 200$.

Fig. 8. Surface and glandular epithelium of IUD 'contact' endometrium. $\times 200$.

Fro. 9. Surface epithelium of IUD 'non-contact' endometrium. $\times 200$.

Figs. 10 and 11. Surface epithelium of IUD 'contact' endometrium. $\times 200$ and 500 .

Frg. 12. Detail of control surface epithelium: corpus luteum aged 7 days. $\times 500$.

Frg. 13. Detail of IUD 'contact' surface epithelium to show leucocytes: corpus luteum aged 7 days. $\times 500$.

\section{PLATE 3}

All the figures are photographs of $8 \mu$ paraffin sections stained with $\mathrm{H}$ and $\mathrm{E}$. Fic. 14. Deciduomal reaction in control, ovariectomized monkey. $\times 40$.

FIGs. 15 and 16. Deciduomal reactions in IUD, ovariectomized monkeys. $\times 40$ and 75 .

Fig. 17. Detail of surface epithelium of control, cyclic monkey to show epithelial 'proliferative cells'. $\times 500$.

FIG. 18. Deciduomal reaction in control, cyclic monkey. $\times 75$.

Fra. 19. Deciduomal reaction in IUD, cyclic monkey. $\times 75$. 
PLATE 1
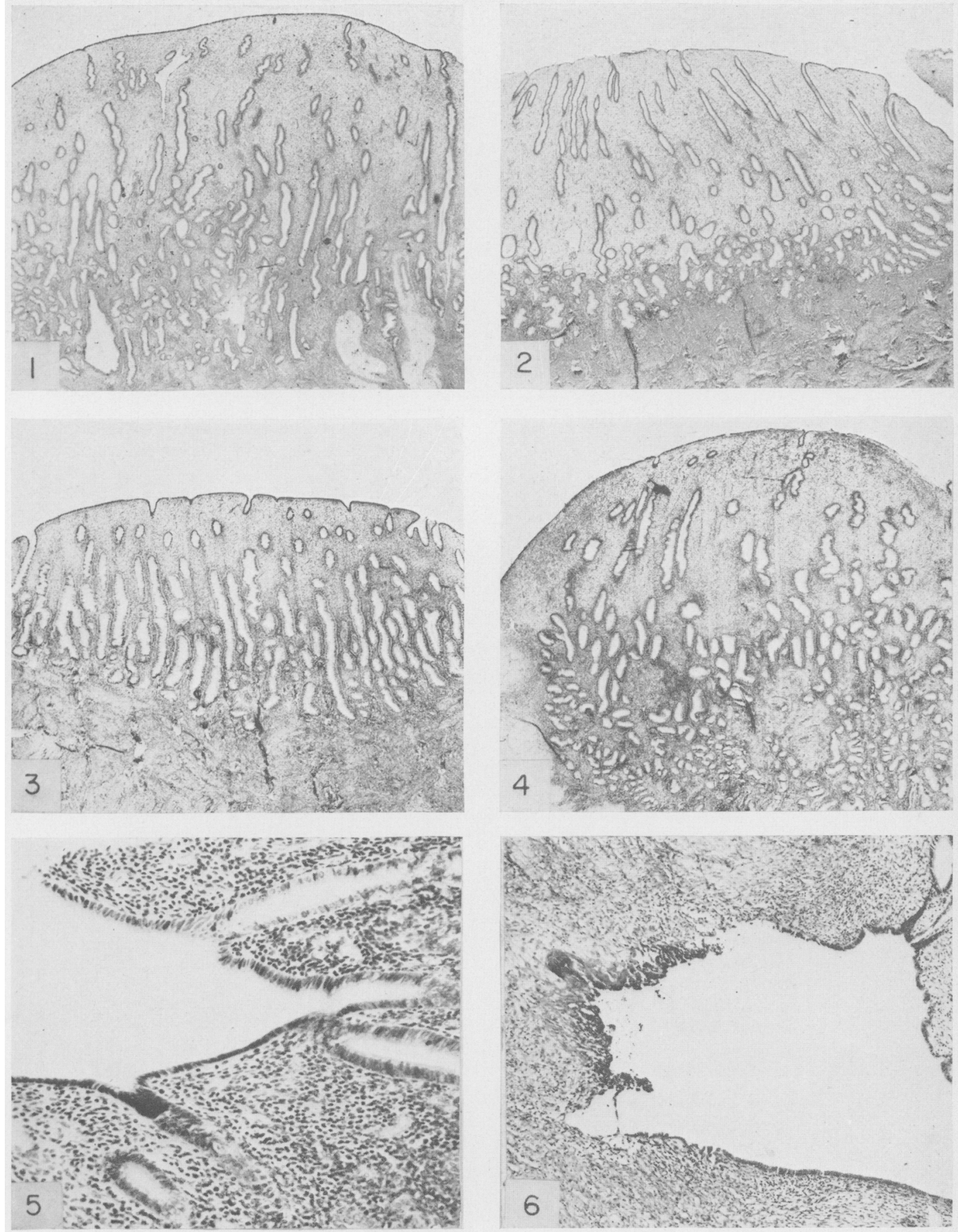

(lucing p. 340) 
PLATE 2
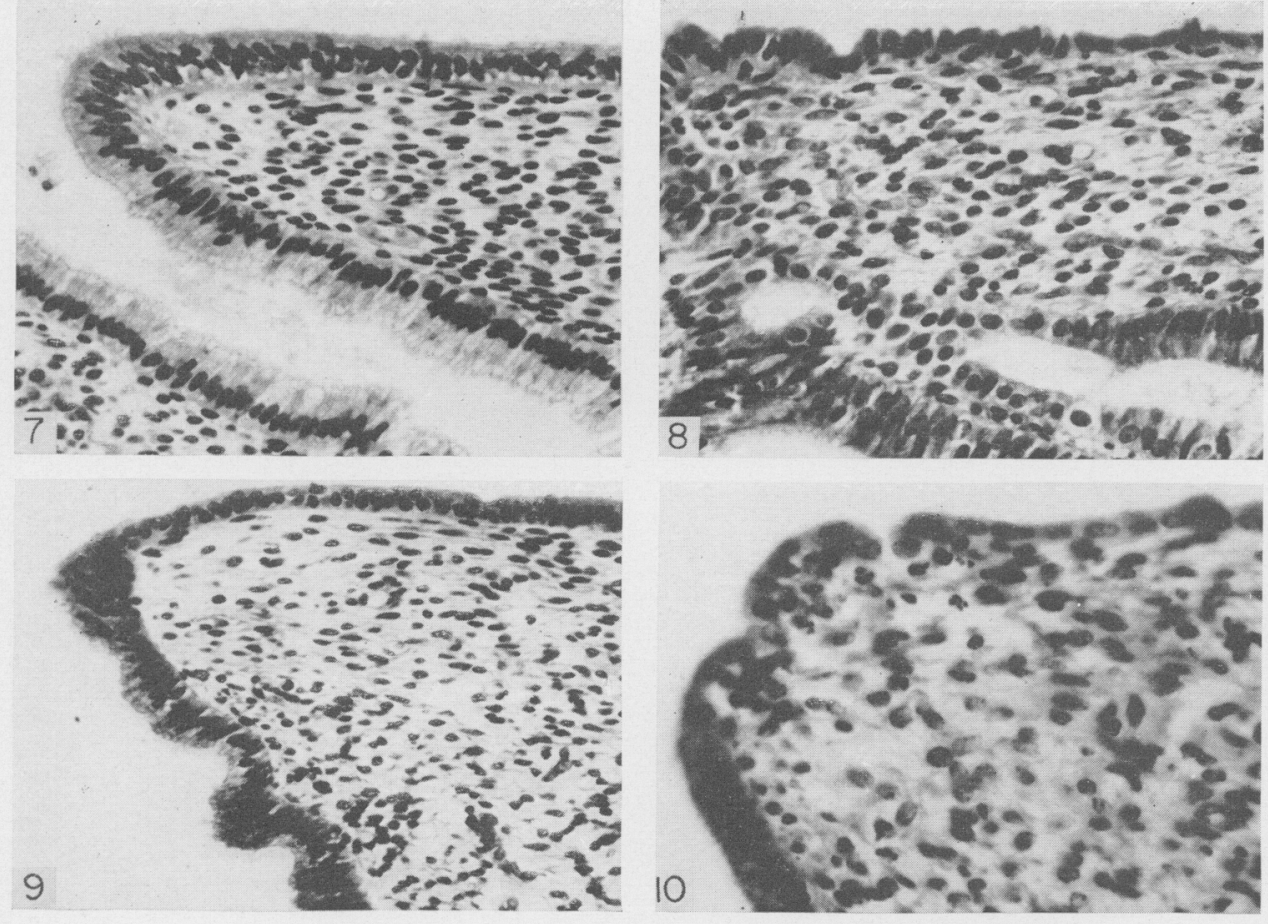

102020

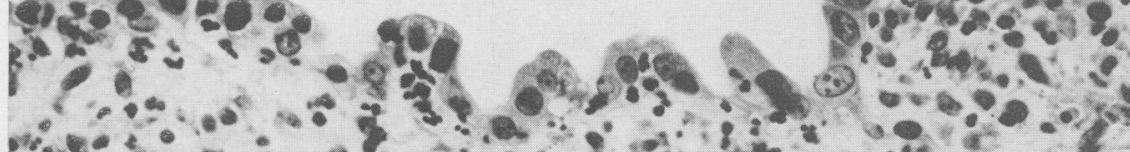

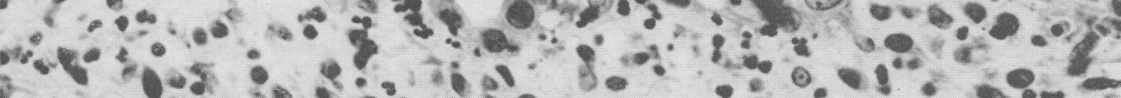

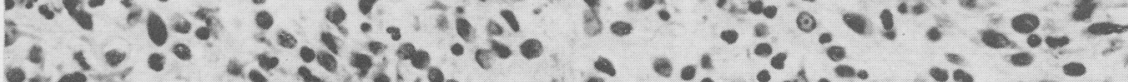
$8+1000 \%$

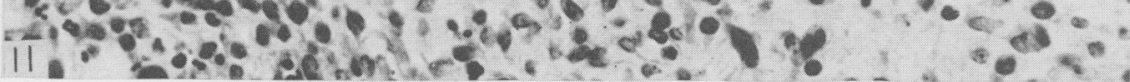
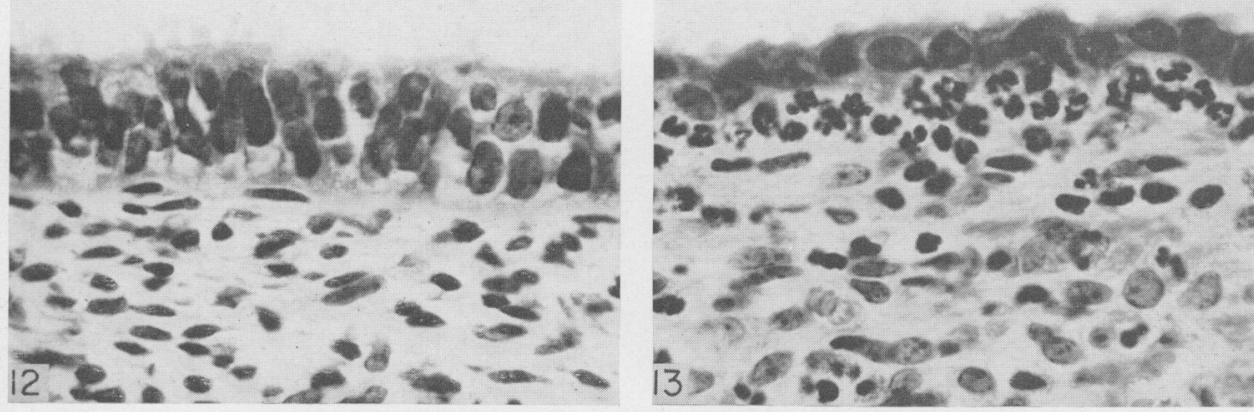


\section{PIATE 3}
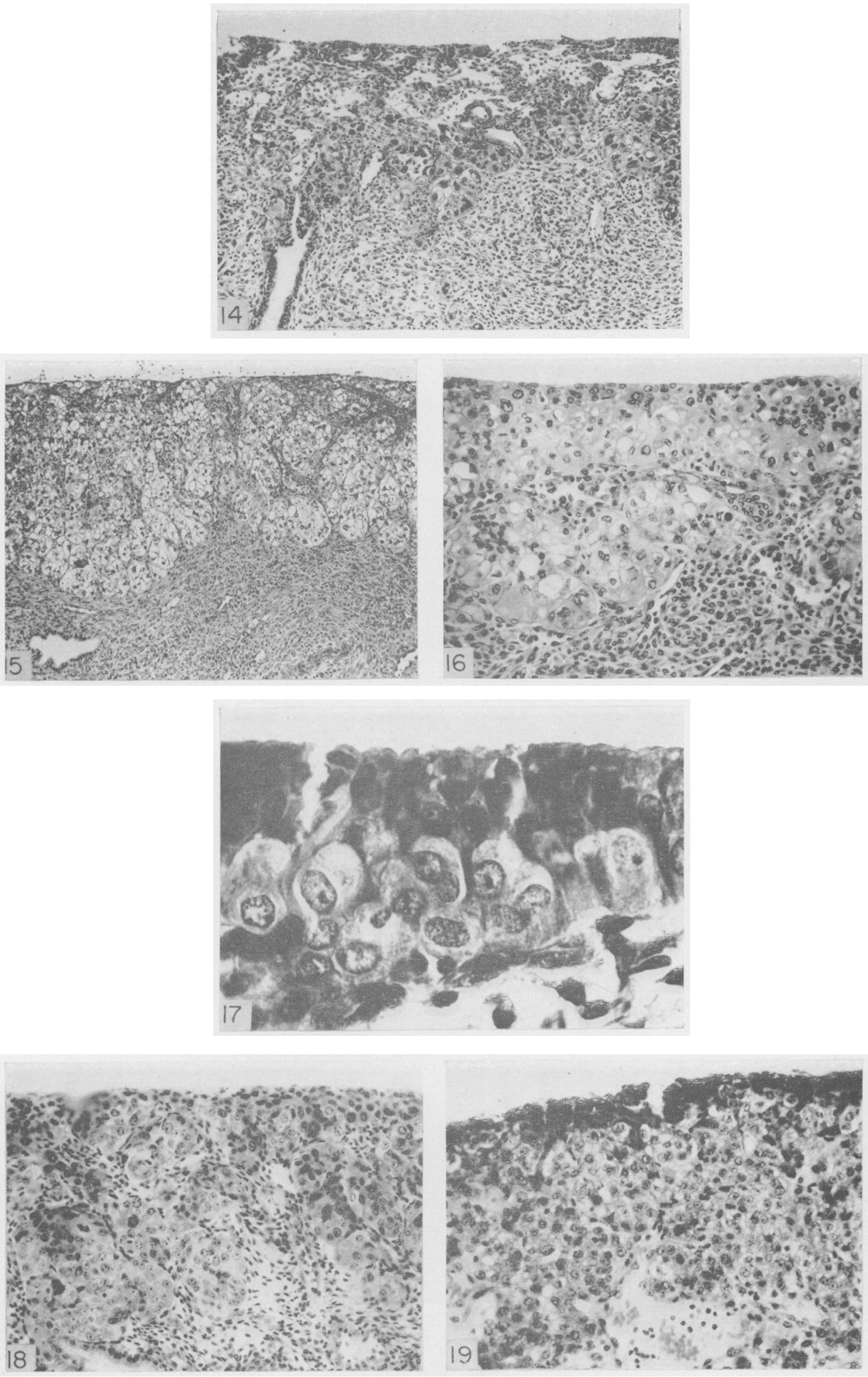